Int. J. Electrochem. Sci., 15 (2020) $8837-8848$

\title{
Electrochemical and Computational Investigations on the Corrosion Inhibition of X65 Steel by 2-Phenylbenzimidazole in $\mathrm{H}_{2} \mathrm{SO}_{4}$ Solution
}

\author{
Jianhong Tan ${ }^{1}$, Lei Guo ${ }^{2,3^{*}}$, Dan Wu ${ }^{1}$, Xuejing Duan ${ }^{1}$, Senlin Leng ${ }^{2}$, Ime Bassey Obot ${ }^{4}$, Savaş Kaya ${ }^{5}$ \\ ${ }^{1}$ School of Chemistry and Chemical Engineering, Yangtze Normal University, Chongqing 408100, \\ China \\ ${ }^{2}$ School of Material and Chemical Engineering, Tongren University, Tongren 554300, China \\ ${ }^{3}$ Material Corrosion and Protection Key Laboratory of Sichuan province, Sichuan University of \\ Science and Engineering, Zigong 643000, China \\ ${ }^{4}$ Center of Research Excellence in Corrosion, King Fahd University of Petroleum and Minerals, \\ Dhahran 31261, Saudi Arabia \\ ${ }^{5}$ Department of Chemistry, Faculty of Science, Cumhuriyet University, Sivas 58140, Turkey \\ *E-mail: cqglei@163.com
}

doi: $10.20964 / 2020.09 .52$

Received: 11 April 2020 / Accepted: 6 July 2020 / Published: 10 August 2020

In this work, we studied 2-phenylbenzimidazole (PBI) as a corrosion inhibitor for $\mathrm{X} 65$ steel in $\mathrm{H}_{2} \mathrm{SO}_{4}$ medium. The inhibition performance of PBI for X65 steel were studied using weight loss, electrochemical experiments, surface analysis and computational modelings. The results indicate that PBI has a superior anti-corrosion performance and belongs to modest cathodic-type corrosion inhibitor. The adsorption behavior of PBI molecule on steel conforms to Langmuir adsorption model. The adsorption type is a combination of physical and chemical adsorption. SEM morphology analysis can prove inhibition performance of PBI. DFT calculation and molecular dynamics simulations have revealed active adsorption sites and adsorption configuration of PBI molecule on Fe substrate.

Keywords: Corrosion, X65 steel, Acid inhibitor, Electrochemistry, Weight loss

\section{FULL TEXT}

(C) 2020 The Authors. Published by ESG (www.electrochemsci.org). This article is an open access article distributed under the terms and conditions of the Creative Commons Attribution license (http://creativecommons.org/licenses/by/4.0/). 